THE influence of a medical education in cultivating earnestness of purpose and developing peculiar and inherent talents, of whatever kind, is illustrated in almost every department of knowledge, "from grave to gay, from lively to severe." Of the thousands who derive entertainment from the unflagging wit of our modern Democritus, Mr. Albert Smith, few know that he is a duly-qualified surgeon. The new superintendent of the Natural History department of the British Museum, Richard Owen is a Fellow of the Royal College of Surgeons. Our most balented mineralogist, and lecturer at the Government School of Mines, Dr. Percy, practised for many years in Birmingham. Indeed, there is scarcely a branch of arts or sciences in which members of the profession have not conspicuously excelled. The newly-appointed Bishop of Ripon formerly studied at St. Thomas's Hospital, and became a M.R.C.S. and L.S.A. before he entered the church. This is the more remarkable, as Mr. Bickersteth is now scarcely past his fortieth year.

That "one fool makes many," we were long ago told; how many, we may estimate from the returns of the numbers of skaters and sliders on our public waters after two days of frost last week. On the Regent's-park water, there were upwards of 5000 persons, although before the evening the ice was entirely broken up. On the long water at Kensington-gardens were 1550, by whom, reports Mr. Williams, the superintendent, the ice was "broken all to pieces."

In the account of the arrangements of the Humane Society, with their tents, hat baths, \&c., all in readiness, no mention was made of any provisions to test the method of resuscitation recently proposed by Dr. Marshall Hall. This was, we trust, merely an omission on the part of the reporter, since the views of this great physiologist are not only entitled to the most careful consideration, but their neglect might perchance cause the remaining spark-if scintilla forsan lateat - to be extinguished by the employment of warm baths and the other routine treatment which Dr. Hall condemns. We have noticed this subject at p. 654 .

THE dentists are proceeding very cautiously, and with great judgment, in their endeavours to raise the character of the profession to which they belong. They are about to hold another meeting for the election of officers and passing of bye-laws. In the meantime, they have given an outline of their intentions by circulars forwarded to those who respectably pursue their calling. Therein it is declared that any chicanery or imposition shall disqualify persons so acting from being members of the Association, and that in glaring cases they will proceed against anyone calling himself a dentist without a fitting qualification. If they are true to themselves, they can hardly fail to accomplish their laudable object, but the reformers should specially guard againgt any dissension. Let them adopt a forceps for their device, with the motto "Pull together."

IT is a great reproach to our much-vaunted English commonwense, that those who wish to thoroughly and practically attain a knowledge of anatomy, are often driven to Paris or other continental schools. In England, the expense of oft-repeated dissections deters many, and the impossibility of obtaining a sufficient supply of subjects hinders more, from ever gaining that deeply-ingrained knowledge of anatomy so essential to successful practice. The same "society" which expects us to devote the greater part of our lives, and the most valuable portions of our time, to gratuitous attendance on the sick, readily listens to and supports every ignorant prejudice which folly or affectation can devise to deprive us of the means of obtaining that knowledge which forms the foundation of our art. The charlatan, ignoring anatomy and learning, has his filthy trash protected by a Government stamp. He may post his bills on the very walls of the temple of science, and use the "divine afflatus" for his puffs. He may blcw his own trumpet, to delude those who, deceived by him, will hear nothing more till the last trump sounds, and he is fostered and protected; while a deaf ear is turned to every solicitation for additional means of acquiring correct knowledge and obtaining information for the benefit of the sick and the alleviation of disease. Tos! h an ? extent is this carried, that even criminals $w$, die $w$ expiating their ill deeds are carefully buried, as $₫:$ Woolwich, in a graveyard of their own, and, after lives of wr ng-doing, are not even allowed to benefit their fellow-creasiares when they are dead.

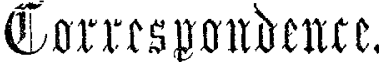

$$
\text { "Audi alteram partem." }
$$

\section{GRIEVANCES AT ST. BARTHOLOMEW'S HOSPITAL.}

To the Editor of The LANCET.

Srr,-Your well-known readiness to expose abuses, and to assist the student at all times, by allowing him to state in. your journal, any hospital grievance he may be labouring under, and to obtain for him, if possible, redress, induces me respect fully to solicit a space in your columns as early as convenient.

The grievance to which I refer originates in that department of St. Bartholomew's over which Dr. West exclusively pre. sides, and I think that yo. will agree with me, when I have stated the case, that it is a very serious one, involving, as it does, the interests, as well as the future prospects, of all those who, in after life, when they will be called upon at the bed-side to give an opinion respecting the disease that any woman may be labouring under, should be satisfactorily prepared to give any explanation that may be required of them.

A question may very naturally be asked-How is it that at a large school like St. Bartholomew's abuses are permitted to exist, where the students are so numerous, and have such power? The fact is, that students do not like to state them, for fear of rendering themselves obnoxious, and getting themselves a bad name with the medical officers; and so with respect to this grierance, I have repeatedly heard students complain, and when I have suggested that they should state it publicly, I have almost invariably received the following reply: " When I go up to the Midwifery Board, I shall most surely be plucked,"-forgetting that the examining boards have no interest in rejecting a pupil, and they take none of his precedents, as to whether he was a disturber of order, into consideration-they either accept or reject him, and are influenced solely by the results of his examination. At all events, I am not at all afraid that any observations I may make will be used and recorded against me when I appear before the Midwifery Board. In this way, the matter is allowed to go on, and one generation of students pass away with their education on that particular point deficient; they are replaced by others, and they likewise admit the evil, but take no notice of it, till at last one student, perhaps a little bolder than the rest, and who may have, perhaps, some little influence over them, brings the grievance before the profession in your journal. Then his fellow students rally around him, and with loud, clamorous voices insist upon tine removal of the grievance. No lecturer, be he who he may, unless he is thoroughly popular and beloved by the pupils, can withstand such influence, for it would be perfectly impossible for him to carry on the business of the session. In other words, he must either yield or retire.

The students have expressed a very natural and very proper desire, and one which I think onght to be immediately gratified without any demur, - namely, that when an operation is required on any of Dr. West's patients, due notice should be given of it to the pupils by posting the same in the usual place. as early as possible on the day of the operation, and also the hour of its performance. Thus every pupil would have an opportunity of knowing what was going on. In the second place, that the operations, instead of being performed in the wards, be brought to the place appointed for such things, namely, the operating theatre. And here, before I proceed any further, let me be allowed to state that nothing is further from my intention than in any way to include or implicate in my observations Mr. Paget,-a gentleman who is beloved and respected by all the pupils. He performs these operations to 
oblige Dr. West, and to Dr. West alone my remarks on this subject apply, and to him only all the blame must be attached. A late clinical clerk of his, a man well qualified to give an opinion on this subject, informed me that he had frequently heard women protest against operations taking place in the wards. Dr. West seems to be a man of feeling; surely it must occur to him that, with serious cases in his wards, it is not likely to do the patients much good. Let us imagine for a moment a poor woman suffering from one of the most dreadful disorders which can befall any of our fellow-creatures: I allude to uterine cancer:-her nightly rest broken by excruciating torments, and her tuneasy hours partially, perhaps, relieved by trifling rest and slight amelioration of pain in the day-time. Is it not essential in such cases to remove every disturbing cause that may excite her nervous and vascular systems? And does Dr. West think that a prolonged and perhaps serious operationthe mere administration of chloroform alone very often occa sioning cries which no patient can distinguish from those of real suffering - should be performed in the ward where such a patient lies?

Having thus shown, I think, that the practice is a wrong one as regards the patients, I shall, in the next place, show its injustice towards the pupils. What is the practice, in the present instance? The operating table is placed near a window, a huge towel-horse placed closely around it covered with sheets, around the area of which Dr. West and his clinical clerks, get. Of course no one would grudge Dr. West the best place; but we think that the secresy and mist which appear to envelop the proceedings of the operator are decidedly objectionable. If any of the students by chance were to get scent of the operation, and were to go up-stairs, they would either see nothing at all, or else have to stand outside kicking their heels, and attempting to look through a thick layer of sheets, which must be very enlivening and edifying to them. But perhaps some of Dr. West's followers-gentlemen who like to keep operations to themselves-might say, what is the use, you can learn nothing-only a few can see it. I answer, that any operation, if persons are selfishly inclined, can be managed in such a way as to prevent people from seeing it. The pupils will not be satisfied by any half concession. Dr. West might take it into his head to retire into Coborn's ward, but it is a place ill adapted for students' seeing, and we should have no check or any guarantee that the same apparent secresy which appear to animate the doings in Worthies' ward would not continue. With the patient in the operating theatre, the area well cleared of the heads of those who might wish to obstruct the views of others, every one would have a fair chance of seeing what was going on in the theatre. I am sure the students would hail with delight and welcome Ir. West there, $\mathbf{a s}$ it is there, too, tbat the cases might really be made practical and useful to us, and much good might result from observations, in the same way as the other surgeons are in the habit of making theirs. Dr. West might object to the exposure of the women in the theatre; but I answer, that with the patient under the influence of chloroform and blindfolded, it would be immaterial whether one or a hundred pupils were present. Imagine what the result would be if in all the cases of femoral hernia and large tumours on the labia which are brought down to the theatre to be operated on, the following plan was hit upon-viz., drawing the operating table to the window, erecting a hnge clotheshorse, enveloped with sheeting, around which any of the staff, the house-surgeons, and the dressers were to get, leaving the students to shift for themselves.

In conclusion, I should be sorry to say anything that might tend to wound or hurt the feelings of Dr. West, anonymously or in the public journals. I have grievances of a much more important nature to communicate to you. I think that it is but right that I should come forward boldly to substantiate any charge I may make. If found false, I shall receive that treatment which all calumniators receive; but if, on the other hand, I shall state the truth, there will be immediate necessity for reform. I remain, Sir, your obedient servant,

$$
\begin{aligned}
& \text { C 1, College, St. Bartholomew's Hospital, } \\
& \text { November, 1856. }
\end{aligned}
$$

\section{DEODORIZATION OF THE SEWAGE OF THE METROPOLIS. \\ To the Editor of THE LANCET.}

SIn,-About twelve months ago I wrote and asked you to whom I had better communicate a plan I had conceived to disinfect and deodorize the sewers and sewage of the Metropolis, and you were good enough to advise me to write to Mr. John
Thwaites, the Chairman of the Metropolitan Board of Works. I accordingly addressed a letter to that gentleman, in January of the present year, which he has not had the courtesy to acknowledge, and from which letter I beg to send you the following extracts :-

"My attention has, for some time past, been a good deal occupied with sanitary measures, and I have thought of an original and comprehensive plan for disinfecting and deodor. izing the Metropolis...... My plan is, that the whole of the water-closets in the Metropolis be supplied with a solution of chloride of zinc, or some other chloride, which I believe might be supplied at a cost of about a halfpenny a gallon, or less; you would thus have an enormous quantity of a powerful disinfecting agent passing through the whole of the drainage of London daily. ...... I think you would thus get rid of most of your epidemic diseases...... It would involve the expense of an entire new system of pipage and steam power for the supply, and factories, \&c., for preparing the solution. ..... The advantages arising from this plan would be so great that I do not imagine the expense would be a barrier to its use, particularly when contrasted with those other plans which have been proposed, and which have not the advantage of disinfecting as well as deodorizing every portion of the metropolitan sewers."

When health and life are at stake, as they undoubtedly are from the present defective condition of sanitary measures in London, I am sure I need not apologise for begging you to make public a plan which, however undigested it may at first appear, would obviate much of the present difficulty, and also the apprehension of the miasm of the sewage being wafted back from its out-fall, to be reconsumed by the lungs of the inhabitants of our great Metropolis.

I am, dear Sir, faithfully yours,

Sherborne, Dorset, Dec. 1856 . WILLIAM HIGHMORE, M.D.

\section{THE GREAT SEWERAGE QUESTION. To the Editor of THE LANCET.}

Srr, - I observe in your leader of November 29th, you praise the sewerage plan of Dr. Marshall Hall. No man has a higher opinion of that illustrious philosopher and physician than I have-the Harvey of the present age. I believe the idea of separating the sewerage into that from water-closets and from sinks is not peculiar to him. Now, I shall not enter into many details. No doubt the great difficulty of dealing with sewerage as a matter of economy is its want of concentration as regards the valuable principles which constitute manure. This would be to a great extent obviated by the plan proposed. I shall not enter into minor objections, such as the want of waterclosets in many houses, but proceed to the main one. Is it to be supposed that the excreta from water-closets alone would furnish sufficient fluid to carry off through drains, a distance of miles, all the excreta? Then the matter remaining in the drains might cause a plague worse than the affairs of Croydon. Keeping the two sets of drainage separate would also be a source of difficulty. Nor do I believe that any unconcentrated drainage would pay the expense of railway carriage, and other sources of expense included in the plan.

It appears to me that there are three modes of dealing with the sewerage question,

1st. By turning half the Thames through the sewers, and keeping them constantly washed out, so as to prevent putrefaction in them $\rightarrow$ a course the propriety of which your readers can estimate.

2nd. By carrying the sewerage to a great distance, and either deodorizing it, and obtaining manure from it, or discharging it bodily into the sea, and thus losing its precious contents; or

3rd. Treating the various sewers somewhat as some of the London Companies treat their impure water supply-viz., filtering it so as to get rid of the impurities, but using in this case materials capable of forming with the matters extracted from the river water, valuable manures; such substances, for instance, as ashes, pounded bricks, soot, plasier, and gypsum. Soot, as I have recently ascertained by experiment, is a most powerful deodorizing agent.

By such means the water of sewers might be disinfected, and a residue obtained of value as manure. I write this note in haste; but may request you to give me more space for my views at a future period. Your obedient servant, Gt. Coram-street, Dee. 1856

R. M. GLOVER, M.D.
To the Editor of THE LANCET.

SIR, - With reference to the plan proposed by Dr. Marshall 